\title{
SEGMENTASI KONSUMEN PUPUK NON-SUBSIDI DI PROVINSI NUSA TENGGARA TIMUR
}

Irwan Hermantria

Universitas Airlangga

\begin{abstract}
The main goal of the research is to assist market players in entering the fertilizer market in East Nusa Tenggara by identifying and forming a non-subsidized fertilizer consumer segmentation. It is expected to provide market insight for fertilizer producers and determine targets when entering the non-subsidized fertilizer market. This research is a quantitative type described descriptively. The data collection technique was an interview equipped with a questionnaire with a Likert scale of the score. Respondents were food crop and horticultural farmers who use or have used non-subsidized fertilizers. The data analysis technique was the K-Means cluster analysis method. Research succeeded in forming two segments of farmers using non-subsidized fertilizers, passive farmer segment and innovative farmer segment based on psychographics and consumer behavior segmentation variables. Geographic and demographic variable descriptors described the segment profile.
\end{abstract}

Keywords : Fertilizer; Marketing; Non-subsidized; Segment

Correspondence to : irwan.hermantria-2019@feb.unair.ac.id

\section{ABSTRAK}

Tujuan penelitian ini untuk membantu pelaku pasar dalam memasuki pasar pupuk di Nusa Tenggara Timur dengan mengidentifikasi dan membentuk segmentasi konsumen pupuk non-subsidi. Dengan demikian diharapkan mampu memberikan pengetahuan pasar bagi produsen pupuk dalam menentukan target pasar. Penelitian ini merupakan penelitian kuantitatif yang dideskripsikan secara deskriptif. Teknik pengumpulan data dilakukan melalui wawancara yang dilengkapi dengan kuesioner dengan skor menggunakan skala likert. Responden penelitian ini adalah petani tanaman pangan dan hortikultura yang menggunakan atau pernah menggunakan pupuk non-subsidi. Analisis data menggunakan metode Cluster Analysis K-Means. Penelitian ini berhasil membentuk dua segmen petani pemakai pupuk non-subsidi, yaitu segmen petani pasif dan segmen petani inovatif berdasarkan variabel segmentasi psikografis dan perilaku konsumen. Profil segmen dijelaskan oleh deskriptor variabel geografis dan demografis.

\section{Kata Kunci : : Non-subsidi; Pemasaran; Pupuk; Segmen \\ Riwayat Artikel:}

Received : 24 Februari 2021

Revised : 17 Mei 2021

Accepted : 4 Juni 2021 


\section{PENDAHULUAN}

Melansir pidato Presiden Republik Indonesia Bapak Joko Widodo di Istana Negara dalam sambutannya pada Rapat Kerja Nasional Pembangunan Pertanian Tahun 2021, Senin, 11 Januari 2021, dimana beliau mempertanyakan return bagi negara dari pengucuran anggaran untuk pupuk bersubsidi, yang setiap tahunnya kurang lebih sekitar 30 triliun rupiah. Beliau menegaskan perlunya evaluasi menyeluruh terkait output yang dihasilkan. Menurut Presiden Republik Indonesia Bapak Joko Widodo, mesti ada yang salah, karena subsidi pupuk yang disediakan oleh pemerintah tidak berbanding lurus dengan peningkatan produktivitas pertanian (Hidayat, 2021).

Indonesia dikenal sebagai negara agraris dengan basis pertanian yang memiliki potensi sangat besar, telah menjadikan sektor pertanian menempatkan pada posisi dengan peranan yang sangat krusial, terutama dalam hal penyediaan lapangan pekerjaan informal sebagai sumber pendapatan bagi penduduknya. Selain itu pertanian di Indonesia juga menjadi elemen penting dalam mendukung sektor industri lainnya dari hulu ke hilir. Badan Pusat Statistik (BPS), pada tahun 2019 mencatat bahwa, Indonesia memiliki luas lahan panen (harvested area) seluas 44,178 juta hektar untuk tanaman utama yang dikategorikan ke dalam kelompok (1) tanaman pangan, (2) hortikultura, dan (3) tanaman perkebunan (Tim Penyusun Badan Pusat Statistik Indonesia, 2019).

Dalam rangka pencapaian hasil yang optimal pemerintah negara Republik Indonesia berperan penting dalam menunjang sektor pertanian, salah satunya adalah dengan program pupuk bersubsidi. Pupuk merupakan salah satu faktor produksi yang sangat penting, dimana penggunaan pupuk secara tepat akan menentukan besaran maupun kualitas produk pertanian yang dihasilkan.

Menurut Irawan \& Rochayati (2017), sektor perkebunan kelapa sawit telah menjadi pendorong utama dalam meningkatknya kebutuhan terhadap pupuk, baik organik maupun anorganik di Indonesia. Sejalan dengan perkebunan kelapa sawit yang merupakan sektor pertanian yang paling besar memberikan devisa kepada negara, juga terdapat beberapa komoditas tanaman perkebunan lainnya seperti kakao, kopi, tebu, tembakau dan karet. Sementara untuk komoditas tanaman pangan seperti jagung dan padi. Irawan \& Rochayati (2017), memproyeksikan kebutuhan pupuk anorganik saja pada tahun 2020 adalah 16 Juta ton, dimana perhitungan tersebut dilakukan dengan pendekatan simulasi sistem dinamik.

Pasar pupuk merupakan market yang sangat besar, dimana berdasarkan Survei Pertanian Antar Sensus (SUTAS) BPS Tahun 2018, terdapat sebanyak 22,37 juta rumah tangga pertanian sebagai pengguna potensial pupuk (Tim Penyusun Badan Pusat Statistik, 2018).

Ragimun et al. (2020), menjelaskan bahwa dengan seringnya terjadi kelangkaan pupuk yang hampir berulang setiap tahun, telah menyebabkan pergeseran pasar pupuk dari subsidi ke pasar non-subsidi. Petani tidak punya pilihan, karena tanaman mereka memerlukan pupuk untuk jaminan hasil yang lebih baik. Di sisi lain fenomena ini telah menjadi peluang baru bagi para produsen pupuk komersial untuk mampu memenuhi gap antara permintaan dan ketersediaan. Namun, dengan adanya program pupuk bersubsidi dari pemerintah, dimana dalam praktiknya mengarah pada kebijakan harga yang memiliki tujuan agar petani dapat mengakses pupuk dengan harga murah, telah menciptakan dampak terhadap pasar pupuk yang bersifat dualistik antara pasar pupuk bersubsidi dan pupuk non-subsidi.

Menyikapi fenomena dimana terdapat bulan-bulan atau musim tanam pada wilayah tertentu yang mengalami kelangkaan pupuk seperti yang diutarakan oleh Ragimun et al. (2020), maka diperlukan kajian terhadap sektor pupuk terutama di wilayah Indonesia bagian timur untuk mendukung para produsen pupuk dalam hal memahami konsumen, sehingga mampu mengurangi dampak destruktif akibat dualistik pasar pupuk yang ada. Para produsen pupuk komersial perlu memahami siapa dan dimana pangsa pasar mereka, faktor-faktor apa saja yang membuat konsumen bersedia menggunakan pupuk komersial, serta pada segmen mana mereka harus bekerja agar terbebas dari dampak 
dualistik pasar pupuk di Indonesia yang memberikan kesan seolah-olah pupuk komersial sangat mahal dibandingkan dengan pupuk bersubsidi.

Fokus penelitian ini adalah di Provinsi Nusa Tenggara Timur (NTT) yang mana pasokan pupuk melalui skema subsidi dari pemerintah sebesar 117,511 Ton berdasarkan alokasi subsidi pemerintah tahun 2020 melalui Peraturan Menteri Pertanian Nomor 01 Tahun 2020 Tentang Alokasi Dan Harga Eceran Tertinggi Pupuk Bersubsidi Sektor Pertanian Tahun Anggaran 2020 (2020), untuk melayani kebutuhan dengan total luas areal panen (harvested area) sebesar 932,722 Ha (Tim Penyusun Badan Pusat Statistik Indonesia, 2019). Hasil olah data kebutuhan pupuk di Provinsi Nusa Tenggara Timur berdasarkan rekomendasi dosis pupuk untuk tanaman pangan, hortikultura dan perkebunan terhadap total luas areal panen (harvested area) untuk masing-masing kategori tanaman, didapati pasokan dari pupuk bersubsidi hanya mampu memenuhi potensi kebutuhan pupuk sebanyak $20 \%$.

Oleh karena itu perlu didorong peran serta produsen pupuk komersial dalam mengisi gap antara kebutuhan dan ketersediaan pupuk. Menciptakan pasar yang sehat menjadi kebutuhan dalam rangka menjaga dan meningkatkan persaingan atau kompetisi antar pelaku usaha pupuk agar tercapainya kesetimbangan harga pupuk yang mengacu pada mekanisme pasar (Susilowati, 2016)

Pamoengkas (2020), menjelaskan bahwa dengan adanya kompetisi antar pelaku pasar di sektor industri pupuk akan memberikan banyak pilihan kepada petani untuk mengakses pupuk yang berkualitas. Oleh karena itu dalam meningkatkan daya saing dan busisness performance, maka pelaku pasar di industri pupuk di dorong untuk merumuskan strategi pada orientasi pasar dan penciptaan nilai (market orientation and value creation). Orientasi pasar (pelanggan) dilakukan dengan tujuan untuk memahami keinginan pelanggan, kebutuhan pelanggan, dan harapan pelanggan.

Dalam industri pupuk, yang disebut pelanggan (konsumen) pupuk terdiri dari dari dua kelompok, pertama adalah konsumen pupuk dari kalangan perusahaan yang bergerak di bidang budidaya pertanian (plantation), kedua adalah konsumen pupuk yang merupakan petani individu (Food and Agriculture Organization, 2005). Dalam penelitian ini, pengertian konsumen pupuk dibatasi pada petani individu, yaitu semua petani pemilik usaha (bukan pekerja pertanian) pengguna pupuk non-subsidi, yang terlibat dalam usaha pertanian tanaman pangan dan hortikultura di Provinsi Nusa Tenggara Timur.

Dalam menerapkan strategi orientasi pasar dan penciptaan nilai (market orientation and value creation), para pelaku pasar di industri pupuk, dituntut untuk mengenal dan memahami siapa pelanggan (konsumen) mereka. Untuk tujuan tersebut, perlu dilakukan identifikasi segmentasi dalam penentuan target pasar (Shah et al., 2019). Segmentasi pasar sendiri diartikan sebagai suatu proses untuk memisahkan pelanggan ke dalam kelompok atau kerumunan yang memiliki karakteristik yang berbeda dengan kelompok yang lainnya.

\section{Tantangan Pasar Pupuk di NTT}

Keterbatasan kajian dan informasi pasar terkait dengan pupuk non-subsidi, lebih spesifik lagi mengenai segmentasi pasar pupuk non-subsidi di NTT telah menjadi salah satu kelemahan bagi para pelaku pasar dalam merumuskan strategi yang berorientasi pada pelanggan (petani). Atas dasar tersebut, maka penelitian ini ditujukan untuk membantu para pelaku pasar dalam sektor pupuk di NTT dengan jalan melakukan identifikasi dan kajian terhadap segmentasikan pasar (end consumer segmentation) pupuk non-subsidi.

Adapun manfaat yang bisa diperoleh dari temuan penelitian ini, antara lain:

a. Menjadi sumber pengetahuan pasar (market insight) yang berkaitan dengan segmentasi pasar bagi para produsen pupuk sehingga mampu menentukan target dalam memasuki pasar pupuk nonsubsidi di Provinsi Nusa Tenggara Timur.

b. Memberikan pengetahuan mengenai pasar pupuk non-subsidi bagi para pengambil kebijakan di Nusa Tenggara Timur. 
Segmentasi Pasar (Market Segmentation)

Kotler \& Keller (2016), menjelaskan bahwa untuk bersaing lebih efektif, banyak perusahaan saat ini berusaha merangkul target pasar mereka. Alih-alih memperluas upaya pemasaran, mereka fokus pada upaya untuk memperbaiki tingkat kepuasan konsumen yang mereka miliki.

Dalam menentukan target pemasaran yang efektif mengharuskan pemasar melakukan beberapa hal berikut:

a. Identifikasi dan profiling kelompok konsumen sesuai kebutuhan dan keinginan mereka yang berbeda-beda (segmentasi pasar).

b. Memilih segmen pasar yang akan dijadikan sebagai target (target market). Pemilihan segmen sebagai target pasar bisa bersifat menyeluruh atau berfokus pada satu atau beberapa segmen saja.

c. Mengembangkan model komunikasi sesuai dengan manfaat produk yang ditawarkan perusahaan pada setiap segmen yang ditarget (positioning).

Segmentasi pasar secara singkat adalah proses membedakan kelompok pembeli berdasarkan perbedaan kebutuhan, karakteristik, dan perilaku di dalam suatu pasar (Kotler \& Keller, 2016). Lebih lanjut Shah et al. (2019), menyatakan bahwa istilah segmentasi bersifat terpisah sehubungan dengan efek dan kecenderungan untuk menghasilkan identifikasi pola permintaan. Segmentasi dengan kata sederhana adalah klasifikasi pasar dengan permintaan heterogen menjadi segmen kecil dengan permintaan homogen.

Segmentasi pasar menjadi penting, karena memiliki tujuan memahami lebih dalam terkait kebutuhan, karakteristik atau perilaku konsumen yang berbeda, sehingga perusahaan mampu menciptakan produk atau value yang memiliki bauran pemasaran tersendiri. Secara lebih luas manfaat segmentasi adalah sebagai berikut:

a. Mengarahkan pada pencocokan yang lebih dekat antara kebutuhan pelanggan dengan produk atau layanan dari perusahaan.

b. Mengarahkan pada pemasaran ceruk (niche market). Jika sesuai, perusahaan dapat memenuhi kebutuhan pelanggan dalam segmen ceruk (niche) yang menjadikannya sebagai aktor dominan pada segmen tersebut, sesuatu yang seringkali tidak mungkin dilakukan di pasar pada umumnya.

c. Memungkinkan dalam mengatur fokus dan konsentrasi sumber daya di pasar untuk mencapai keunggulan kompetitif terbesar dan keuntungan yang tinggi.

d. Meraih keunggulan kompetitif yang memungkinkan perusahaan melihat pasar dengan cara yang berbeda dari para pesaing.

e. Memungkinkan perusahaan menjadi spesialis pada segmen yang menjadi pilihan.

Untuk melakukan segmentasi pasar dapat dilakukan dengan banyak cara dan didasarkan pada banyak variabel. Variabel yang digunakan untuk segmentasi pasar dibagi menjadi tiga kelompok besar, yaitu, latar belakang karakteristik pelanggan, sikap pelanggan dan perilaku pelanggan.

Latar belakang karakteristik pelanggan dianggap sebagai mengkategorikan informasi. Atribut sikap pelanggan adalah hal yang berkaitan dengan hubungan sebab akibat antara atribut pelanggan dan perilaku pemasaran. Karakteristik perilaku mempertimbangkan perilaku pelanggan terhadap penawaran pasar dari berbagai aspek. Variabel segmentasi hampir serupa di berbagai studi. Namun, klasifikasi mereka yang lebih luas berbeda dalam hal jumlah dan istilah. Yang terpenting adalah variabel yang digunakan sebagai dasar segmentasi, bukan klasifikasi yang lebih luas (Shah et al., 2019).

Sementara Kotler \& Keller (2016:2454) lebih rinci membedakan variabel segmen pasar menjadi 4 kelompok yaitu:

1. Segmentasi Geografis (Geographic Segmentation). Konsumen dikelompokan berdasarkan perbedaan wilayah menurut batasan administratif geografis yang diakui secara umum. seperti negara, provinsi, Kabupaten, kota, atau bahkan sampai pada level lingkungan sebuah komunitas.

2. Segmentasi Demografis (Demographic Segmentation). Segmentasi demografi membedakan segmen pasar pada perbedaan kelompok pasar yang 
didasarkan pada atribut demografi seperti usia, jenis kelamin, pekerjaan, penghasilan, pendidikan, agama, suku, jumlah orang dalam keluarga, kewarganegaraan, kelas sosial, orientasi politik dan sebagainya.

3. Segmentasi Psikografis (Psycographic Segmentation). Segmentasi psikografi mengelompokan pasar dari hasil memahami psikologi dari konsumen. Contohnya pengelompokan konsumen berdasarkan gaya hidup, kepribadian atau norma masyarakat yang dianut.

4. Segmentasi Perilaku Konsumen (Behaviour Segmentation). Pendekatan segmentasi perilaku membedakan konsumen menjadi kelompok-kelompok berdasarkan pengetahuan (knowledge), sikap (acceptance), status penggunaan dan perspektif terhadap suatu produk.

Segmentasi pasar adalah salah satu konsep yang banyak digunakan dalam pemasaran, digunakan di bidang seperti aktivitas fisik, gaya hidup. Ide dasar segmentasi adalah untuk membagi populasi, pasar, atau audiens menjadi kelompok yang anggotanya lebih mirip satu sama lain daripada anggota segmen lain (Arli et al., 2020).

Dalam literatur pemasaran, nilai yang dirasakan didefinisikan sebagai trade-off dari total manfaat yang diterima oleh konsumen dengan total pengorbanan yang dialami oleh konsumen. Aktivitas pemasaran yang sukses, perusahaan harus mampu menciptakan nilai guna merangkul konsumen sebagai imbalannya. Pada titik ini, nilai dari produk atau jasa tertentu menjadi acuan penting bagi konsumen terkait dengan perilaku membeli. Mengacu pada teori nilai konsumsi, bahwa alasan utama mengapa konsumen memiliki perilaku yang berbeda terhadap suatu produk tertentu adalah karena konsumen mempersepsikan lima nilai yang mungkin, seperti nilai fungsional, kondisional, sosial, emosional dan epistemik (Fauzi \& Sheng, 2020).

Sementara itu, juga terdapat argumen yang mendukung hubungan antara psikologi dan perilaku konsumen. Ketika mengaitkan psikologi dengan perilaku konsumsi, terlihat bahwa secara umum, barang berfungsi sebagai sinyal dari sifat yang diinginkan dan membawa status kepada konsumen (Stephen \& Gbadamosi, 2021).

Dalam kontek psikologi, dikaitkan dengan emosional konsumen. Terdapat dua pendekatan mendasar untuk menganalisis emosi, yaitu dimensional (berbasis valensi) dan kategorikal (kekhususan emosi). Dalam literatur psikologi sosial menunjukkan bahwa individu terkait erat dengan masyarakat mereka Emosi memotivasi perilaku, memiliki durasi yang singkat, berumur pendek dalam bidang kesadaran dan memerlukan perhatian segera (Santos et al., 2021).

Dari sisi perilaku juga terdapat argumen yang mengkaitkan dengan budaya yang juga merupakan faktor utama yang menentukan apa yang dikonsumsi oleh banyak orang. Hal tersebut dapat mendefinisikan produk apa yang dianggap dapat diterima atau tidak dapat diterima, dan baik atau buruk dalam suatu komunitas tertentu (Stephen \& Gbadamosi, 2021). Pada akhirnya, perilaku konsumen akan meliputi niat beli terus menerus. Konsep niat beli berkelanjutan mirip dengan niat membeli kembali dalam perilaku konsumen (Safeer et al., 2021).

\section{Kerangka Konseptual}

Penelitian ini menganalisis kombinasi faktor-faktor yang menjadi alasan para konsumen untuk membeli pupuk non-subsidi dan perilaku pelanggan. Dimana alasan-alasan yang akan ditanyakan melalui kuesioner merupakan indikator-indikator pembentuk variabel psikografi dan perilaku (behaviour) yang menjadi dasar dalam melakukan segmentasi. Selanjutnya variabel demografi akan digunakan dalam profiling segmen. 


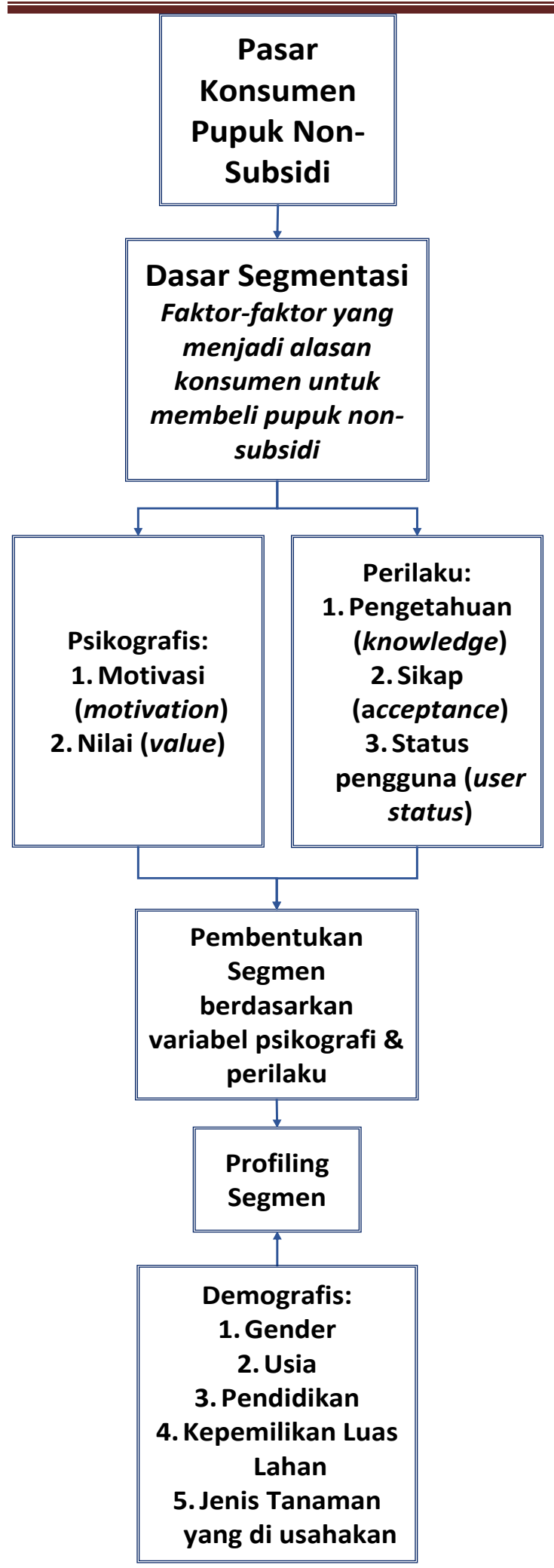

Gambar. 1

Ilustrasi tahapan dalam segmentasi pasar menurut Kotler \& Keller (2016)

\section{METODE PENELITIAN}

Jenis penelitian ini termasuk ke dalam penelitian kuantitatif dengan pendekatan deskriptif. Dimana dalam penelitian ini melibatkan analisis dalam membahas tujuan penelitian melalui penilaian empiris yang berdasarkan pada pengukuran numerik. Sedangkan pendekatan deskriptif ditujukan untuk menegaskan dan menjelaskan karakteristik dari variabel yang diteliti pada kondisi tertentu (Zikmund et al., 2013:55,132).

Variabel yang digunakan meliputi variabel psikografis, perilaku (behaviour) dan demografis sebagai dasar untuk membentuk atau menentukan segmen yang belum didentifikasi di pasar.

\section{Definisi Operasional Variabel}

Penetapan definisi operasional variabel perlu dilakukan agar terhindar dari kesalahan dalam mengartikan variabel yang diukur pada penelitian, serta menjelaskan secara terperinci mengenai variabel yang diturunkan menjadi beberapa indikator, ukuran, dan skala (Zikmund et al., 2013). Selanjutnya indikator dari variabel-variabel yang menjadi dasar dalam segmentasi pengguna pupuk nonsubsidi di Provinsi Nusa Tenggara Timur diuraikan sebagai berikut:

1. Psikografis (psycographic)

Dalam penelitian ini, merujuk pada dua atribut yang menjelaskan variabel psikografi sebagai dasar segmentasi menurut Kotler \& Keller (2016), yaitu:

a. Atribut motivasi

b. Atribut value yang diharapkan

2. Perilaku (behaviour)

Dalam penelitian ini, merujuk pada tiga atribut yang menjelaskan variabel perilaku (behaviour) sebagai dasar segmentasi merujuk pada penelitian Sadílek, (2019), yaitu:

a. Pengetahuan (knowledge)

b. Sikap (acceptance)

c. Status (user status)

3. Demografis (demographic)

Dalam penelitian ini, atribut yang menjelaskan variabel demografi sebagai dasar segmentasi merujuk kepada (Kotler \& Keller, 2016), yaitu: (a) gender, (b) 
kelompok umur, (c) tingkat pendidikan, (d) sumber penghasilan atau jenis usaha, (e) kepemilikan dan (f) besarnya pengeluaran.

Untuk pengukurannya dalam penelitian ini dilakukan dengan tingkat kesetujuan skala likert dengan nilai 1 sampai 5. Dengan skala likert, responden mengindikasikan sikap atau cara berpikirnya dengan melakukan pengecekan seberapa kuatnya mereka setuju atau tidak setuju secara hati-hati dalam merespon setiap pernyataan. Range skala likert dimulai dari jawaban responden sangat tidak setuju hingga sangat sangat setuju dengan alternatif pilihan jawaban sebagai berikut:

$$
\begin{aligned}
& 1=\text { Sangat tidak setuju } \\
& 2=\text { Tidak setuju } \\
& 3=\text { Netral } \\
& 4=\text { Setuju } \\
& 5=\text { Sangat setuju }
\end{aligned}
$$

\section{Jenis dan Sumber Data}

Data yang dianalisis dalam penelitian ini adalah data kuantitatif, yang terdiri dari angka-angka yang memiliki makna dan mewakili fenomena yang sedang dianalisis (Zikmund et al., 2013:651).

Sumber data dalam penelitian berasal dari data primer dan data sekunder. Data primer dihasilkan secara langsung oleh peneliti untuk tujuan spesifik penelitian ini. Dimana dalam menghasilkan data primer peneliti melakukan wawancara (face to face interview) (Sekaran \& Bougie, 2016:38). Sedangkan data sekunder merupakan kompilasi data yang diperoleh dari hasil penelitian sebelumnya, jurnal, laporan dan publikasi dari instansi pemerintahan (Levine et al., 2017:39-40).

\section{Populasi dan Sampel}

Karakteristik populasi yang menjadi objek kajian dalam penelitian ini adalah semua petani (rumah tangga petani) pemilik usaha (bukan pekerja pertanian), yang menggunakan atau pernah menggunakan pupuk non-subsidi dalam usaha pertanian tanaman pangan dan hortikultura di Provinsi Nusa Tenggara Timur.

Berdasarkan Survei Pertanian Antar Sensus (SUTAS) BPS Tahun 2018, di Provinsi Nusa Tenggara Timur terdapat 497,852 jumlah rumah tangga usaha pertanian yang terlibat dalam pengusahaan tanaman pangan dan hortikultura (Badan Pusat Statistik Indonesia, 2018:49).

Sampel diartikan sebagai subset atau bagian kecil dari populasi yang lebih besar. Tujuan pengambilan sampel untuk memperkirakan karakteristik yang tidak diketahui dari suatu populasi (Zikmund et al., 2013:387).

Penentuan sampel dilakukan dengan pendekatan sampel klaster (cluster sampling), dengan tujuan ekonomis namun tetap mempertahankan karakteristik sampel probabilitas (Zikmund et al., 2013:401).

Dalam penelitian ini lokasi sampel ditentukan pada level kabupaten yang menjadi sumber produksi utama pertanian dan mewakili tiga pulau utama yang terdapat di Provinsi Nusa Tenggara Timur. Kabupaten yang termasuk ke dalam pengambilan sampel yaitu Kab. Timur Tengah Utara, Kab. Timur Tengah Selatan, Kab. Ende, Kab. Manggarai, Kab. Sikka dan Kab.Sumbawa barat.

Sementara untuk sampel responden dari tiap-tiap kabupaten yang dipilih akan dilakukan secara acak (simple random sampling). Dimana dengan teknik sampel acak akan memberikan peluang yang sama bagi setiap elemen yang ada di dalam populasi (Zikmund et al., 2013:398).

Perhitungan jumlah sampel penelitian, peneliti menggunakan parameter perhitungan pada confident level $90 \%$ dan margin of error $5 \%$, didapatkan jumlah sampel yang dibutuhkan adalah sebanyak 273 responden. Dasar perhitungan jumlah sampel merujuk pada rumus:

$$
\text { Sample size }=\frac{\frac{z^{2} \times p(1-p)}{e^{2}}}{1+\left(\frac{z^{2} \times p(1-p)}{e^{2} N}\right)}
$$

Dimana:

$\mathrm{N}=$ Jumlah populasi

$\mathrm{e}=$ Margin of error

$\mathrm{z}=$ z-score

\section{Teknik Analisis Data}

Untuk melakukan segmentasi sesuai dengan tujuan dari penelitian ini, peneliti 
menggunakan metode pengelompokan (cluster analysis) dan tabulasi silang (cross tab).

Metode pengelompokan dalam analisis data menggunakan teknik non-hirarki ( $K$ Means Cluster). Tahapan analisis data dengan teknik ini, menurut Hair Jr et al. (2018) dilakukan sebagai berikut:

1. Standardisasi data

Data yang dikumpulkan melalui survei bisa jadi memiliki variabilitas satuan, oleh karena itu dibutuhkan standardisasi pada data variabel yang akan dianalisis ke dalam bentuk zscore.

2. Menentukan jumlah klaster yang akan dibentuk.

3. Melakukan pengelompokan dengan teknik non-hiraki (K-Means cluster).

4. Melakukan uji signifikan dari setiap variabel pembentuk klaster berdasarkan tabel anova.

5. Interpretasi klaster berdasarkan final cluster centre serta pemberian nama berdasarkan variabel clustering.

6. Memvalidasi dan membuat profil klaster.

Tabulasi silang (cross tab) digunakan dalam membuat profil klaster. Diperlukan dasar deskriptor yang dapat menjelaskan kelompok atau klaster yang terbentuk, yaitu atribut-atribut dalam variabel geografi dan demografi.

\section{HASIL PENELITIAN}

Dalam analisis data dengan teknik nonhirarki (K-Means cluster), peneliti menetapkan sebanyak dua klaster yang akan dibentuk. Variabel pembentuk yang digunakan adalah variabel psikografi dan perilaku yang menghasilkan penciri sebagai karakteristik masing-masing segmen. Langkah awal yang mesti dilakukan adalah standardisasi data. Tabel output dari melakukan standardisasi data yang dijalankan dengan SPSS menampilkan tabel sebagai berikut:
TABEL 1. Descriptive Statistics

\begin{tabular}{llllll}
\hline & N & Min & Max & Mean & $\begin{array}{l}\text { Std. } \\
\text { Deviation }\end{array}$ \\
\hline P1 & 273 & 1.00 & 5.00 & 3.7619 & .86925 \\
\hline P2 & 273 & 1.00 & 5.00 & 3.5934 & .87420 \\
\hline P3 & 273 & 2.00 & 5.00 & 3.0952 & .41800 \\
\hline P4 & 273 & 1.00 & 5.00 & 3.3773 & 1.02207 \\
\hline P5 & 273 & 1.00 & 5.00 & 3.5971 & .88217 \\
\hline P6 & 273 & 1.00 & 5.00 & 3.1392 & .59628 \\
\hline B1 & 273 & 1.00 & 5.00 & 2.7656 & 1.39984 \\
\hline B2 & 273 & 1.00 & 5.00 & 3.7033 & .81115 \\
\hline B3 & 273 & 1.00 & 5.00 & 3.5018 & 1.09183 \\
\hline B4 & 273 & 1.00 & 5.00 & 1.4249 & .97527 \\
\hline B5 & 273 & 1.00 & 5.00 & 3.2491 & 1.22634 \\
\hline B6 & 273 & 1.00 & 4.00 & 2.7692 & 1.15118 \\
\hline B7 & 273 & 1.00 & 5.00 & 3.2125 & 1.15631 \\
\hline B8 & 273 & 1.00 & 5.00 & 2.9451 & 1.00399 \\
\hline B9 & 273 & 1.00 & 5.00 & 3.4432 & 1.20868 \\
\hline B10 & 273 & 1.00 & 5.00 & 4.4139 & 1.06451 \\
\hline B11 & 273 & 1.00 & 4.00 & 2.9597 & .99734 \\
\hline Keter & & & & &
\end{tabular}

Keterangan:

$\mathrm{P} 1=$ Alasan karena hasil panen lebih baik

P2=Alasan karena lebih hemat

P3=Alasan karena kualitas lebih baik

P4=Alasan karena kemudahan menemukan pupuk non-subsidi di kios

P5=Alasan karena kemudahan dalam aplikasi

P6=Alasan karena ketersediaan lebih terjamin

B1=Mengenal pupuk non-subsidi

B2=Memahami kualitas pupuk non-subsidi lebih bagus

B3=Keterlibatan dalam kelompok tani

B4=Penerimaan terhadap harga yang terjangkau

B5=Menggunakan karena pengaruh dari pasangan

B6=Menggunakan karena pengaruh petani lain

B7=Menggunakan karena pengaruh kelompok tani

B8=Menggunakan karena pengaruh staf produsen pupuk

B9=Menggunakan karena pengaruh dari PPL

B10=Aktif dalam mencari informasi

B11=Status menggunakan pupuk nonsubsidi 1 tahun terakhir 
Tabel 1 digunakan sebagai dasar untuk mendapatkan nilai zscore yang dianggap sebagai nilai yang terstandardisasi. Zscore merupakan jarak nilai sebuah data dari mean kelompoknya dalam bentuk nilai deviasi. Zscore dihitung sebagai nilai data dikurangi rata-rata kemudian dibagi dengan standar deviasi.

Dalam melakukan pengelompokan dengan teknik non-hiraki (K-Means cluster), nilai yang digunakan sebagai data tidak lagi data awalnya, tetapi menggunakan nilai zscore yang telah didapatkan.

TABEL 2. Initial Cluster Centers

\begin{tabular}{crr}
\hline & \multicolumn{2}{c}{ Cluster } \\
\cline { 2 - 3 } & \multicolumn{1}{c}{$\mathbf{2}$} \\
\hline ZP1 & -2.02692 & .27391 \\
\hline ZP2 & -1.82271 & .46510 \\
\hline ZP3 & -2.62022 & 4.55690 \\
\hline ZP4 & -2.32595 & 1.58767 \\
\hline ZP5 & -1.81038 & 1.59031 \\
\hline ZP6 & -.23344 & 3.12067 \\
\hline ZB1 & -.54690 & .88184 \\
\hline ZB2 & .36578 & .36578 \\
\hline ZB3 & .45627 & -1.37552 \\
\hline ZB4 & -.43569 & 2.64040 \\
\hline ZB5 & -1.01855 & -1.01855 \\
\hline ZB6 & 1.06913 & -.66821 \\
\hline ZB7 & -1.04856 & -1.04856 \\
\hline ZB8 & -.94130 & -.94130 \\
\hline ZB9 & 1.28799 & -1.19404 \\
\hline ZB10 & -.38883 & .55056 \\
\hline ZB11 & -1.96493 & 1.04306 \\
\hline Keteran93n & &
\end{tabular}

Keterangan:

$\mathrm{ZP1}=$ Zscore Alasan karena hasil panen lebih baik

$\mathrm{ZP} 2$ = Zscore Alasan karena lebih hemat

$\mathrm{ZP3}=$ Zscore Alasan karena kualitas lebih baik

$\mathrm{ZP4}=$ Zscore Alasan karena kemudahan menemukan pupuk non-subsidi di kios

ZP5 = Zscore Alasan karena kemudahan dalam aplikasi

ZP6 = Zscore Alasan karena ketersediaan lebih terjamin

ZB1 = Zscore Mengenal pupuk nonsubsidi

ZB2 = Zscore Memahami kualitas pupuk non-subsidi lebih bagus
ZB3 = Zscore Keterlibatan dalam kelompok tani
ZB4 = Zscore Penerimaan terhadap harga yang terjangkau
ZB5 = Zscore Menggunakan karena pengaruh dari pasangan
ZB6 = Zscore Menggunakan karena pengaruh petani lain
ZB7 = Zscore Menggunakan karena pengaruh kelompok tani
ZB8 = Zscore Menggunakan karena pengaruh staf produsen pupuk
ZB9 = Zscore Menggunakan karena pengaruh dari PPL
$\mathrm{ZB} 10=$ Zscore Aktif dalam mencari informasi
ZB11 = Zscore Status menggunakan pupuk non-subsidi 1 tahun terakhir

Tabel 2 menggambarkan pembentukan awal klaster berdasarkan nilai zscore sebelum proses iterasi dilakukan.

TABEL 3. Final Cluster Centers

\begin{tabular}{ccc}
\hline & \multicolumn{2}{c}{ Cluster } \\
\cline { 2 - 3 } & $\mathbf{1}$ & $\mathbf{2}$ \\
\hline ZP1 & -.64955 & $\mathbf{. 7 5 7 8 1}$ \\
\hline ZP2 & -.63989 & $\mathbf{. 7 4 6 5 4}$ \\
\hline ZP3 & -.14647 & $\mathbf{. 1 7 0 8 8}$ \\
\hline ZP4 & -.47564 & $\mathbf{. 5 5 4 9 1}$ \\
\hline ZP5 & -.61513 & $\mathbf{. 7 1 7 6 5}$ \\
\hline ZP6 & -.26766 & $\mathbf{. 3 1 2 2 7}$ \\
\hline ZB1 & -.53718 & $\mathbf{. 6 2 6 7 1}$ \\
\hline ZB2 & -.67415 & $\mathbf{. 7 8 6 5 0}$ \\
\hline ZB3 & .03259 & -.03802 \\
\hline ZB4 & -.34501 & $\mathbf{. 4 0 2 5 1}$ \\
\hline ZB5 & -.17538 & $\mathbf{. 2 0 4 6 1}$ \\
\hline ZB6 & -.12455 & $\mathbf{. 1 4 5 3 1}$ \\
\hline ZB7 & .02806 & -.03273 \\
\hline ZB8 & -.16887 & $\mathbf{. 1 9 7 0 2}$ \\
\hline ZB9 & $\mathbf{. 1 1 7 3 3}$ & -.13688 \\
\hline ZB10 & -.15878 & $\mathbf{. 1 8 5 2 4}$ \\
\hline ZB11 & -.51891 & $\mathbf{. 6 0 5 3 9}$ \\
\hline
\end{tabular}

Tabel 3 menjelaskan variabel apa saja yang menjadi pusat klaster yang dibentuk. Nilai (-) menandakan bahwa data dari variabel tersebut di bawah nilai rata-rata total. Nilai (+) memiliki arti bahwa data dari variabel tersebut di atas nilai rata-rata total. Nilai positif terbesar pada masing-masing row variabel dianggap sebagai variabel pembentuk klaster. 
Namun sebelum memutuskan apakah suatu variabel merupakan pembeda satu klaster terhadap klaster lainnya, mesti lakukan pengecekan melalui uji signifikan.

Uji signifikan dilakukan dengan melakukan pengecekan pada tabel 4 sebagai berikut.

TABEL 4. Anova

\begin{tabular}{|c|c|c|c|c|}
\hline & \multicolumn{2}{|c|}{ Cluster } & \multicolumn{2}{|c|}{ Error } \\
\hline & $\begin{array}{c}\text { Mean } \\
\text { Square } \\
\end{array}$ & & $\begin{array}{l}\text { Mean } \\
\text { quare }\end{array}$ & df \\
\hline ZP1 & 134.381 & 1 & .508 & 271 \\
\hline $\mathrm{ZP} 2$ & 130.414 & 1 & .522 & 271 \\
\hline ZP3 & 6.833 & 1 & .978 & 271 \\
\hline $\mathrm{ZP} 4$ & 72.054 & 1 & .738 & 271 \\
\hline ZP5 & 120.515 & 1 & .559 & 271 \\
\hline ZP6 & 22.818 & 1 & .919 & 271 \\
\hline ZB1 & 91.907 & 1 & .665 & 271 \\
\hline ZB2 & 144.749 & 1 & .470 & 271 \\
\hline ZB3 & .338 & 1 & 1.002 & 271 \\
\hline ZB4 & 37.911 & 1 & .864 & 271 \\
\hline ZB5 & 9.796 & 1 & .968 & 271 \\
\hline ZB6 & 4.941 & 1 & .985 & 271 \\
\hline ZB7 & .251 & 1 & 1.003 & 271 \\
\hline ZB8 & 9.083 & 1 & .970 & 271 \\
\hline ZB9 & 4.384 & 1 & .988 & 271 \\
\hline ZB10 & 8.030 & 1 & .974 & 271 \\
\hline \multirow[t]{2}{*}{ ZB11 } & 85.761 & 1 & .687 & 271 \\
\hline & \multicolumn{2}{|l|}{$\mathbf{F}$} & \multicolumn{2}{|l|}{ Sig. } \\
\hline ZP1 & \multicolumn{2}{|c|}{264.624} & \multicolumn{2}{|r|}{.000} \\
\hline $\mathrm{ZP} 2$ & \multicolumn{2}{|c|}{249.617} & \multicolumn{2}{|r|}{.000} \\
\hline ZP3 & \multicolumn{2}{|c|}{6.983} & \multicolumn{2}{|r|}{.009} \\
\hline $\mathrm{ZP} 4$ & \multicolumn{2}{|c|}{97.659} & \multicolumn{2}{|r|}{.000} \\
\hline ZP5 & \multicolumn{2}{|c|}{215.595} & \multicolumn{2}{|r|}{.000} \\
\hline ZP6 & \multicolumn{2}{|c|}{24.816} & \multicolumn{2}{|r|}{.000} \\
\hline ZB1 & \multicolumn{2}{|c|}{138.299} & \multicolumn{2}{|r|}{.000} \\
\hline ZB2 & \multicolumn{2}{|c|}{308.266} & \multicolumn{2}{|r|}{.000} \\
\hline ZB3 & \multicolumn{2}{|c|}{.337} & \multicolumn{2}{|r|}{.562} \\
\hline ZB4 & \multicolumn{2}{|c|}{43.889} & \multicolumn{2}{|r|}{.000} \\
\hline ZB5 & \multicolumn{2}{|c|}{10.125} & \multicolumn{2}{|r|}{.002} \\
\hline ZB6 & \multicolumn{2}{|c|}{5.014} & & .026 \\
\hline ZB7 & & & & .617 \\
\hline ZB8 & & & & .002 \\
\hline ZB9 & & & & .036 \\
\hline ZB10 & & & & .004 \\
\hline ZB11 & & & & .000 \\
\hline
\end{tabular}

Berdasarkan uji signifikan, dimana variabel-variabel dengan nilai Sig. $<0,05$, maka di anggap sebagai pembeda pada klasternya. Sehingga dapat disimpulkan bahwa pembentuk klaster 1 adalah ZB9, sedangkan untuk klaster 2 adalah ZP1, ZP2,
ZP3, ZP4, ZP5, ZP6, ZB1, ZB2, ZB4, ZB5, ZB6, ZB8, ZB10 dan ZB11.

\section{PEMBAHASAN}

Berdasarkan karakteristik variabel pembentuk klaster, penulis secara subjektif memberikan nama pada klaster 1 sebagai segmen petani pasif dan nama pada klaster 2 sebagai segmen petani inovatif. Karakteristik masing-masing segmen tersebut dijelaskan secara detail sebagai berikut:

\section{Klaster 1, Segmen Petani Pasif}

Atribut pembentuk segmen ini berasal dari atribut sikap pada variabel perilaku (behaviour), yang mana karakteristik segmen ini cenderung bersifat pasif dan menunggu informasi ataupun arahan dari Petugas Penyuluh Pertanian (PPL) dinas pertanian pemerintah kabupaten. Kelompok ini kurang berinisiatif untuk mencari sumber informasi lain terkait pertanian yang mereka upayakan.

\section{Klaster 2, Segmen Petani Inovatif}

Atribut pembentuk segmen ini berasal dari variabel psikografi dan perilaku (behaviour). Atribut dari variabel psikografi yang membentuk segmen ini adalah atribut motivasi dan value yang diharapkan. Atribut motivasi terkait keinginan untuk memperoleh hasil panen yang lebih baik serta penghematan secara total pada analisa usaha tani mereka melalui penggunaan pupuk yang dianggap lebih berkualitas. Kelompok ini memiliki pemahaman bahwa secara satuan per kilogram pupuk yang digunakan, memang terlihat lebih mahal di awal, namun in return ketika di hitung dari hasil panen yang didapatkan, kelompok ini memahami justru terjadi penghematan untuk cost per unit panen yang dihasilkan. Sementara atribut perilaku (behaviour) yang ikut membentuk segmen ini adalah atribut pengetahuan, sikap dan status pengguna dari petani. Pengetahuan petani terkait penggunaan, tata cara dan kualitas pupuk non-subsidi pada segmen ini cukup mumpuni, yang membuat sikap mereka lebih bisa menerima terhadap perbedaan harga dengan pupuk subsidi. Kelompok ini terbiasa mencari informasi terkait pertanian yang mereka upayakan secara mandiri. Kelompok 
ini lebih terbuka menerima informasi baru dari pasangan, petani lain dan staf lapangan produsen pupuk. Sedikit berlawanan dengan segmen petani pasif, dimana kelompok ini tidak terlalu mengandalkan informasi dan arahan dari Petugas Penyuluh Lapangan (PPL) dinas pemerintahan kabupaten. Kebanyakan petani dalam kelompok ini masih terus menggunakan pupuk non-subsidi untuk pertanian mereka.

\section{Profil Segmen}

Tabulasi silang (cross tab) digunakan dalam membuat profil segmen. Deskriptor yang menjelaskan masing-masing segmen yang dibentuk adalah atribut-atribut dalam variabel geografi dan demografi.

\section{Profil Segmen Petani Pasif}

Dari segi geografis segmen ini tersebar merata di 3 pulau utama yang ada di NTT dengan rincian masing-masing kabupatennya adalah; Kab. Ende 10.2\%, Kab. Manggarai 16.3\%, Kab. Sikka 11.6\%, Kab. Sumba Barat $11.6 \%$, Kab. Timor Tengah Selatan 27.2\% dan Kab. Timor Tengah Utara $23.1 \%$.

Sementara tabulasi yang dilakukan terhadap atribut demografi dijelaskan secara terperinci sebagai berikut.

a. Segmen petani pasif menurut gender Kelompok ini lebih di dominasi oleh petani laki-laki, meski tidak terlalu signifikan perbedaannya. Kelompok gender pada segmen petani pasif adalah laki-laki $57.8 \%$ dan perempuan $42.2 \%$.

b. Segmen petani pasif menurut usia Kelompok ini lebih di dominasi oleh petani dengan rentang usia $31-50$ tahun $61,9 \%$, yang kemudian diikuti oleh petani dengan rentang usia di atas 50 tahun sebanyak $29,9 \%$. Sementara petani gen- $Z$ dengan rentang usia 21 - 30 tahun hanya sebanyak $10,9 \%$.

c. Segmen petani pasif menurut tingkat pendidikan

Kelompok ini lebih di dominasi oleh petani dengan tingkat pendidikan SD SMP / Sederajat sebanyak 73,5\%, yang disusul tingkat pendidikan SMA Diploma sebanyak 22,4\% dan petani yang tidak pernah sekolah sebanyak 2,7\%. Sementara petani dengan tingkat pendidikan tertinggi pada segmen ini, yaitu S1/S2/S3 terdapat sebanyak 1,4\%.

d. Segmen petani pasif menurut tanaman yang diupayakan

Dalam kelompok ini tidak terlalu terbedakan secara signifikan antara petani yang mengupayakan tanaman pangan sebanyak $40,8 \%$ dengan petani yang mengupayakan tanaman hortikultura sebanyak $59,2 \%$.

e. Segmen petani pasif menurut kepemilikan luas lahan

Kelompok ini lebih didominasi oleh petani yang memiliki lahan pada rentang maksimal 0,25 Ha sebanyak 51,7\%, sementara yang lain dengan kepemilikan luas lahan $0,26-0,50 \mathrm{Ha} 22.4 \%, 0,51-1$ Ha $19.0 \%, 1-1,25 \mathrm{Ha} 0.7 \%, 1,76-2 \mathrm{Ha}$ $2.7 \%$ dan $>2$ Ha $3,4 \%$.

f. Segmen petani pasif menurut besarnya pengeluaran untuk biaya pertanian

Kelompok petani ini paling banyak menghabiskan uang untuk biaya pertanian pada rentang 0 - 500 Ribu Rupiah sebanyak $43,5 \%$, sementara pengeluaran untuk biaya pertanian pada rentang lainya adalah 500 Ribu - 1 Juta Rupiah 20.4\%, 1,1 - 2,5 Juta Rupiah $24.5 \%, 2,6$ - 5 Juta Rupiah 8.8\%, 5,1 - 7,5 Juta Rupiah 1.4\%, 7,6 - 10 Juta Rupiah $0.7 \%$ dan > 15 Juta Rupiah $0,7 \%$.

\section{Profil Segmen Petani Inovatif}

Dari segi geografis segmen ini lebih mendominasi di pulau Timor dan tidak terdapat sama sekali di Pulau Sumba. Rincian sebaran segmen ini menurut kabupaten sebagai berikut; Kab. Ende 2.4\%, Kab. Manggarai $0.8 \%$, Kab. Sikka 6.3\%, Kab. Timor Tengah Selatan $11.9 \%$ dan Kab. Timor Tengah Utara $78.6 \%$.

Sementara tabulasi yang dilakukan terhadap atribut demografi dijelaskan secara terperinci sebagai berikut.

a. Segmen petani inovatif menurut gender

Kelompok ini lebih di dominasi oleh petani laki-laki secara signifikan yaitu $66 \%$ terhadap petani perempuan sebanyak $34 \%$.

b. Segmen petani inovatif menurut usia Kelompok ini lebih di dominasi oleh petani dengan kelompok usia $41-50$ 
tahun 35\%, yang kemudian diikuti oleh petani dengan kelompok usia $31-40$ tahun $22,2 \%$, rentang usia $51-60$ tahun 20,6 dan petani dengan usia di atas 60 tahun dan petani gen- $Z$ dengan kelompok usia 21 - 30 tahun masing-masingnya memiliki jumlah yang sama sebanyak $11,1 \%$.

c. Segmen petani inovatif menurut tingkat pendidikan

Kelompok ini lebih di dominasi oleh petani dengan tingkat pendidikan SD SMP / Sederajat sebanyak 70\%, yang disusul tingkat pendidikan SMA Diploma sebanyak $24 \%$ dan petani yang tidak pernah sekolah sebanyak 2,4\%. Menariknya terdapat petani dengan tingkat pendidikan yang lebih tinggi yaitu $\mathrm{S} 1 / \mathrm{S} 2 / \mathrm{S} 3$ terdapat sebanyak $4 \%$ yang jauh lebih banyak dua kali lipat dari segmen petani pasif.

d. Segmen petani inovatif menurut tanaman yang diupayakan

Dalam kelompok ini terdapat perbedaan yang sangat signifikan antara petani yang mengupayakan tanaman pangan sebanyak $21,4 \%$ dengan petani yang mengupayakan tanaman hortikultura yang jauh lebih dominan sebanyak 78,6\%.

e. Segmen petani inovatif menurut kepemilikan luas lahan

Tidak jauh berbeda dengan segmen petani pasif, segmen petani inovatif juga lebih didominasi oleh petani yang memiliki lahan pada rentang maksimal $0,25 \mathrm{Ha}$ sebanyak $52,4 \%$, sementara yang lain dengan kepemilikan luas lahan 0,26-0,50 Ha 27\%, 0,51 - 1 Ha 15.1\%, $1-1,25 \mathrm{Ha}$ $0.8 \%, 1,26-1,50$ Ha 2,4\%, 1,76-2 На $1,6 \%$ dan $>2$ Ha $1,6 \%$.

f. Segmen petani inovatif menurut besarnya pengeluaran untuk biaya pertanian

Kelompok petani ini paling banyak menghabiskan uang untuk biaya pertanian pada rentang 0 - 500 Ribu Rupiah sebanyak 50\%, sementara pengeluaran untuk biaya pertanian pada rentang lainya adalah 500 Ribu - 1 Juta Rupiah 16,7\%, 1,1 - 2,5 Juta Rupiah 15,1\%, 2,6 - 5 Juta Rupiah 15,1\%, 5,1 - 7,5 Juta Rupiah 1,6\%, 7,6 - 10 Juta Rupiah 1,6\% dan tidak ada petani yang menghabiskan biaya $>15$ Juta Rupiah pada segmen ini.

\section{KESIMPULAN}

Dengan pembentukan kedua segmen petani pengguna pupuk non-subsidi di Provinsi Nusa Tenggara Timur, yaitu segmen petani pasif dan segmen petani inovatif, dimana kedua segmen tersebut memiliki karakteristik penciri yang sangat berbeda secara signifikan, maka dalam upaya berkontribusi untuk mengurangi gap ketersediaan pupuk terhadap permintaan yang seringkali terjadi setiap tahunnya, disarankan para produsen pupuk untuk menjadikan segmen petani inovatif sebagai target pasar yang secara karakteristik dari segmen ini sangat memberi peluang bagi para produsen pupuk untuk dapat menghindari dampak negatif dari kebijakan harga pupuk bersubsidi bagi pelaku pasar. Dengan pengetahuan akan segmen ini, produsen pupuk dapat merancang marketing communication yang efektif yang sesuai dengan profil dari segmen petani inovatif untuk di jadikan sebagai target pasar. Hal ini akan menjadi alternatif solusi bersama bagi para stakeholder yang berkaitan dengan pupuk di Provinsi Nusa Tenggara Timur. Pemerintah menjadi terbantu atas permasalahan kelangkaan pupuk pada waktuwaktu tertentu yang terjadi berulang setiap tahunnya, dan dari sisi produsen pupuk, mendapatkan pangsa pasar baru di wilayah Provinsi Nusa Tenggara Timur.

Besar harapan penulis, bahwa penelitian ini menjadi awal yang baik bagi penelitianpenelitian selanjutnya yang lebih luas terkait pemasaran pada sektor pupuk di Provinsi Nusa Tenggara Timur.

\section{DAFTAR PUSTAKA}

Arli, D., Tjiptono, F., Tkaczynski, A., \& Bakpayev, M. (2020). Grit: the good, the bad and the ugly. Asia Pacific Journal of Marketing and Logistics, 33 No.5, 1270-1285. https://doi.org/10.1108/APJML-042020-0271

Fauzi, A. A., \& Sheng, M. L. (2020). Ride- 
hailing apps' continuance intention among different consumer groups in Indonesia: the role of personal innovativeness and perceived utilitarian and hedonic value. Asia Pacific Journal of Marketing and Logistics, 33(5), 1195-1219.

https://doi.org/10.1108/APJML-052019-0332

Food and Agriculture Organization. (2005). Fertilizer Use by Crop in Indonesia. http://www.fao.org/tempref/agl/agll/doc s/fertuseindonesia.pdf

Hair Jr, J. F., William, C. B., Babin, B. J., \& Anderson, R. E. (2018). Multivariate Data Analysis (8th ed.). Cengage.

Hidayat, A. A. N. (2021). Subsidi Pupuk Rp 33 T Tiap Tahun, Jokowi: Return-nya Apa? Ini Ada yang Salah. https://bisnis.tempo.co/read/1422104/su bsidi-pupuk-rp-33-t-tiap-tahun-jokowireturn-nya-apa-ini-ada-yang-salah

Irawan, D. S., \& Rochayati, S. (2017). Proyeksi kebutuhan pupuk sektor pertanian melalui pendekatan sistem dinamis. Bogor, Balai Penelitian Tanah, 12, 123-139.

Peraturan Menteri Pertanian Nomor 01 Tahun 2020 Tentang Alokasi dan Harga Eceran Tertinggi Pupuk Bersubsidi Sektor Pertanian Tahun Anggaran 2020, Pub. L. No. Nomor 01 (2020). http://ditlin.tanamanpangan.pertanian.go .id/assets/front/uploads/document/PER MENTAN NOMOR 01 TAHUN 2020 ed.pdf

Kotler, P., \& Keller, K. L. (2016). Marketing Management Global Edition (Vol. 15E). Pearson. https://doi.org/10.1080/0891176090302 2556

Levine, D. M., Stephan, D. F., \& Szabat, K. A. (2017). Statistics for Managers Using Microsoft Excel, 8th Edition (8th Editio). Pearson Education Limited.

Pamoengkas, I. (2020). Market Orientation and Value Creation in Improving Business Performance of the Fertilizer
Industry in Indonesia. European

Research Studies Journal, XXIII(Issue 1), 143-152. https://doi.org/10.35808/ersj/1567

Ragimun, Makmun, \& Setiawan, S. (2020). Strategi Penyaluran Pupuk Bersubsidi Di Indonesia. Jurnal Ilmiah M-

Progress, 10(1), 1-21.

https://journal.universitassuryadarma.ac. id/index.php/ilmiahmprogress/article/view/369

Sadílek, T. (2019). Consumer preferences regarding food quality labels: the case of Czechia. British Food Journal, 121(10), 2508-2523. https://doi.org/10.1108/BFJ-03-20190150

Safeer, A. A., He, Y., Lin, Y., Abrar, M., \& Nawas, Z. (2021). Impact of perceived brand authenticity on consumer behavior : an evidence from generation $\mathrm{Y}$ in Asian perspective. Brand Authenticity on Consumer Behavior, 71772074. https://doi.org/10.1108/IJOEM-092020-1128

Santos, V., Ramos, P., Sousa, B., Almeida, N., \& Valeri, M. (2021). Factors influencing touristic consumer behaviour. Journal of Organizational Change Management, 54(0953-4814). https://doi.org/10.17221/283-agricecon

Sekaran, U., \& Bougie, R. (2016). Research Methods for Business, A Skill-Building Approach, 7th Edition (7th Editio). John Wiley \& Sons Ltd.

Shah, S. A., Azhar, S. M., \& Bhutto, N. A. (2019). Halal marketing: a marketing strategy perspective. Journal of Islamic Marketing, 11(6), 1641-1655. https://doi.org/10.1108/JIMA-11-20180211

Stephen, C. M. E., \& Gbadamosi, A. (2021). Hedonism and luxury fashion consumption among Black African women in the UK : an empirical study. Journal of Fashion Marketing and Management: An International Journal. https://doi.org/10.1108/JFMM-05-2020- 
0079

Susilowati, S. H. (2016). Urgensi Dan Opsi Perubahan Kebijakan Subsidi Pupuk Urgent Policy Changes in Fertilizer Subsidy. Analisi Kebijakan Pertanian, 14(2), 163-185.

Tim Penyusun Badan Pusat Statistik. (2018). Hasil Survei Pertanian Antar Sensus (SUTAS) 2018 Nasional. In Badan Pusat Statistika.

Tim Penyusun Badan Pusat Statistik Indonesia. (2019). Statistik Indonesia 2019 - Statistical Yearbook of Indonesia 2019.

Zikmund, W., Babin, B., Carr, J., \& Griffin, M. (2013). Business Research Methods 9th Edition. In Cengage Learning. 